\title{
ROLAND DUHAMEL ÜBER METALITERATUR
}

Roland Duhamel: Dichter im Spiegel. Über Metaliteratur. Würzburg (Königshausen \& Neumann) 2001.72 S.

Das schmale Bändchen, das der Antwerpener Germanist Roland Duhamel hier vorlegt, ist ein großer Wurf. Anders als der Titel suggerieren könnte, handelt es nicht nur von literarischen Dichterdarstellungen, vom produktiven Umgang mit historischen Dichtergestalten in der späteren Literatur, es will vielmehr als Ausgleich zur Tradition der "akademischen", philosophischen Ästhetik eine Geschichte der werkimmanenten Ästhetik für die deutsche Literatur seit Goethe schreiben. Metaliteratur wird hier, in der Abgrenzung zur Metafiktion, "die die Artifizialität ausschließlich narrativer Strukturen zum Thema erhebt", als die (literarische) Beschäftigung nicht nur mit dem "Bild der Dichterfiguren in der Fiktion, sondern auch [mit] deren Auffassungen von Sprache, Literatur und Schreiben" (6) verstanden. Die Literaturwissenschaft sollte sich, so fordert Duhamel, verstärkt der Literatur selber zuwenden und so verhüten, daß die "literarische Neugier" der Studenten "in der akademischen Wüste der Fachtheorien" (7) ersticke. Er setzt sich zum Ziel, "das Phänomen und die Geschichte der deutschsprachigen Metaliteratur zu präsentieren ohne Zuhilfenahme externer Faktoren wie der Zeitgeschichte und der philosophischen Ästhetik" (7). Ob dies in der hier apostrophierten Stringenz überhaupt gelingen kann, fragt sich: implizit kommen Geschichte, Zeit und Gesellschaft schon zum Tragen, denn thematisiert wird nicht nur das Verhältnis der Literatur zu sich selbst, sondern auch das von Literatur und Dichter zum Leben, zur außerliterarischen Wahrheit sowie zum jeweiligen sozialen Kontext; Selbstreflexion von Literatur und Dichter bezieht unweigerlich auch deren (zeitspezifischen) Funktionszusammenhang mit ein. Kapitelüberschriften wie "Literatur und Engagement" (Kap. 2) sowie "Literatur und Moral" (Kap. 6) bestätigen dies einmal mehr.

Duhamel betrachtet die Geschichte der Metaliteratur seit Goethes Tasso (1790) als einen großen Bußgang, der dem Verlust der Unschuld nachtrauert, die sich um 1800 für kurze Zeit einzustellen schien, als der philosophisch-ästhetische und der metaliterarische Traditionsstrang kurzfristig verschmolzen, in dem (früh)romantischen 
Glauben eines Hölderlin oder eines Novalis, daß “die Dichtung [...] der intuitiven Erfassung des Wahren und Wesentlichen fähig" (9) sei. Dieser Glaube sei, so heißt es weiter im ersten Kapitel, das "Literatur und Wahrheit" überschrieben ist, von Neuromantikern wie Rilke zwar erneut zelebriert worden, geblieben sei aber im Grunde vom romantischen Konzept nur die Idee vom authentischen Schreiben, mit der etwa noch Frisch ringe. Die Bußmetapher prägt Duhamels Darstellung der deutschen Metaliteratur: sie sei "die schriftliche Beichte der Literatur. Es geht um Schuldbekenntnis und Selbstvorwürfe; hier wird gelitten und gebüßt" (8), "literarische Gewissens[er]forschung" (58) kennzeichne noch Walsers Ohne einander (1993), und in der Zusammenfassung am Schluß (Kap. 10) heißt es prägnant: "Metaliteratur ist der Bußgesang der Literaturgeschichte", denn immer wieder hätten "Schriftsteller ihre Frustrationen und die ihrer Epoche dem Konto ihres Umgangs mit dem Wort gutgeschrieben" (69), worin, so sei nebenbei hervorgehoben, erneut der sich trotz allem geltend machende Zeitbezug anklingt.

Seit der verlorengegangenen Einheit der Romantik hinterfragt Metaliteratur Teilwahrheiten und Einzelwirklichkeiten als Alternative für das Abhandengekommene. Sie werden von Duhamel in den weiteren Kapiteln thematisiert. Wo Literatur sich engagiert (Kap. 2: "Literatur und Engagement"), richtet sich die metaliterarische Perspektive auf die "politische Wahrheit" (16); richtungweisend sei hier Brecht gewesen, aber Weiss' Ästhetik des Widerstands (19751981) sei das schlechthinnige "Standardwerk der politischen Metaliteratur" (19). In der Auseinandersetzung der Literatur mit den "nihilistischen Tendenzen der Moderne" (20) gewahrt Duhamel drei Ausprägungen von Metaliteratur: eine, die im Zeichen des "literarischen Nihilismus" (Kap. 3) steht und als einzige Wahrheit verkündet, daß es keine Wahrheit gebe, wie sich etwa an Ransmayrs Letzte Welt (1988) exemplifizieren lasse; eine weitere, die mit dem Oberbegriff des "linguistischen Nihilismus" (Kap. 4) zu erfassen wäre, das fragwürdige Verhältnis von Sprache und Wirklichkeit problematisiert und als deren bekanntester Vertreter Hofmannsthals Chandos-Brief (1901/02) gilt, der aber auch etwa Johnson, Celan und Bachmann zuzuzählen seien; und eine dritte schließlich, die im Erkenntnis des Korrespondenz-Kohärenz-Dilemmas beim dichterischen Umgang mit dem Wahrheitsbegriff im "philosophischen Nihilismus" (Kap. 5) wurzelt, wie er sich in Kafkas Prozeß (1914) artikuliert, und die den Dichter als grundsätzlichen Lügner ansieht. Wo Literatur dem Nihi- 
lismus verhaftet ist, muß sie als "moralisch unanständig, verworfen und verderblich" (36) gelten, kann sie sich nur als "Sünde" (36) begreifen (Kap. 6: "Literatur und Moral"), was sich in der Thematisierung des Verhältnisses von Künstler und Bürger etwa bei Thomas Mann, Thomas Bernhard und Brecht niederschlägt.

Alle vorher erwähnten Teilaspekte konvergieren gleichsam im 7. Kapitel, das sich unter der Überschrift "Die dichterische Legitimationskrise" mit der literarischen Dichterdarstellung befaßt. Es bildet das Herzstück von Duhamels Darlegungen. Als im Nihilismus Befangener, an der Verlogenheit der eigenen Tätigkeit Leidender muß der Dichter, seit Goethes Tasso, gleichsam an sich selbst zugrunde gehen. Dies wird mitsamt den unterschiedlichen Nuancen an einer Fülle von Werken aufgezeigt: von Goethe über Tieck, Bonaventura und Eichendorf bis hin zu Weiss und Härtling, an Lenz-Darstellungen von Büchner, Peter Schneider und Gert Hofmann sowie an Hinterfragungen der dichterischen Existenz ohne eine konkrete Anbindung an eine historische Dichtergestalt bei Christa Wolf und Wolfgang Hilbig, um nur einige zu nennen. Ein eigenes, letztes Kapitel (Kap. 8: "Literatur und Existenz") beschäftigt sich mit der metaliterarischen Problematisierung des Dichters oder Künstlers, nicht in dessen Eigenschaft als Kunstschaffender, sondern als "Prototyp des modernen, d.h. verfremdeten, unbehausten Menschen" (61) schlechthin. Hier reicht das Spektrum von Hesses Steppenwolf (1927) bis zu der existentiellen Einbettung von Künstlergestalten bei Thomas Bernhard.

Duhamels Darstellung kann zweifellos in einigen Punkten kritisiert werden; so fragt sich etwa, ob er bei der Auswahl der zugrundeliegenden Texte nicht allzu selektiv.vorgegangen ist und ob die modernen Dichterdarstellungen tatsächlich ausnahmslos das tragische Scheitern an der Doppelheit der Dichterexistenz thematisieren, insgesamt aber überzeugt sein anregender Neuansatz einer Literaturgeschichtsschreibung von der werkimmanenten Ästhetik der Metaliteratur her durchaus. Der Aufbau der Untersuchung ist logisch und kohärent. Alle Achtung verdient die stupende Belesenheit, die aus ihr spricht. Zu hoffen ist, daß die hier präsentierten Ansätze künftig weiter ausgebaut werden.

Guillaume van Gemert 